\title{
An Activated CD8 + Lymphocyte Appears in Lymph Nodes of Rhesus Monkeys Early after Infection with Simian Immunodeficiency Virus
}

\author{
Keith A. Reimann, Gregory B. Snyder, Laura V. Chalifoux, Barry C. D. Waite, Michael D. Miller, \\ Hiroshi Yamamoto, Olivier Spertini, * and Norman L. Letvin \\ New England Regional Primate Research Center, Harvard Medical School, Southborough, Massachusetts 01772 and ${ }^{*}$ Division \\ of Tumor Immunology, Dana-Farber Cancer Institute, Harvard Medical School, Boston, Massachusetts 02115
}

\begin{abstract}
Although alterations in $\mathbf{T}$ lymphocyte subset distribution and function in the peripheral blood of HIV-infected humans are well defined, the extent to which these reflect changes in other lymphoid compartments is unclear. We have characterized the coincident changes in PBL and lymph nodes (LN) ${ }^{1}$ after simian immunodeficiency virus of macaques $\left(\mathbf{S I V}_{\operatorname{mac}}\right)$ infection of rhesus monkeys. Whereas no consistent change in CD8+ PBL was noted during the first 60 d after infection, CD8+ lymphocytes increased significantly in number in LN. These CD8 + LN lymphocytes exhibited an increased expression of MHC class II and a decreased expression of leukocyte adhesion molecule-1, suggesting that they were activated, but interestingly did not express CD25 (IL-2 receptor). Moreover, there was no evidence that these CD8 + LN cells were proliferating, suggesting that they had migrated to the LN. These changes in the LN CD8+ lymphocyte population preceded any detectable change in the light microscopic appearance of the LN. When SIV max- $_{\text {- }}$ specific effector $T$ cell responses were assessed, the magnitude of virus-specific effector activity was nearly identical in the PBL and $L N$ of each monkey studied. However, the presence of SIV $_{\text {mac }}$-specific effector cells in the LN did not correlate with the presence of $\mathrm{CD8}+$, MHC class II+ cells. These findings suggest that this numerically important CD8+ lymphocyte subpopulation may serve a regulatory function. (J. Clin. Invest. 1991. 88:1113-1120.) Key words: acquired immune deficiency syndrome $\bullet$ cytotoxic $\mathrm{T}$ lymphocyte $\bullet$ MHC class II $\bullet$ regulatory $\mathrm{T}$ lymphocyte $\bullet \mathrm{T}$ lymphocyte subset
\end{abstract}

\section{Introduction}

Immunologic mechanisms to control the spread of a virus are activated soon after infection of the host. The nature of this response in man after infection by HIV, and in particular the cellular immune response to this virus, remains poorly understood. Examination of the early immune response to HIV in-

Address correspondence to Keith A. Reimann, New England Regional Primate Research Center, Harvard Medical School, One Pine Hill Drive, Southborough, MA 01772.

Received for publication 15 January 1991 and in revised form 29 April 1991.

1. Abbreviations used in this paper: CTL, cytotoxic T lymphocyte; LAM-1, leukocyte adhesion molecule-1; LN, lymph node; SIV $_{\text {mac }}$, simian immunodeficiency virus of macaques.

J. Clin. Invest.

(C) The American Society for Clinical Investigation, Inc.

$0021-9738 / 91 / 10 / 1113 / 08 \quad \$ 2.00$

Volume 88, October 1991, 1113-1120 fection is hampered by the subclinical nature of this initial infection. Moreover, important early immunologic responses likely occur in lymphoid organs; these responses may not even be apparent in the peripheral blood (1).

The simian immunodeficiency virus of macaques $\left(\operatorname{SIV}_{\mathrm{mac}}\right)^{1}$ is a lentivirus with biologic and genetic similarity to HIV (2). When inoculated into rhesus monkeys, this virus induces an AIDS-like disease which has striking similarities to AIDS in man (3). We have utilized the $\mathrm{SIV}_{\text {mad }}$ /rhesus monkey model to study prospectively the $\mathrm{T}$ lymphocyte changes which occur in lymph nodes (LN) after infection with SIV $_{\text {mac }}$. In these studies we show that an activated CD8+ lymphocyte without demonstrable virus-specific effector function is a major, early component of the host immune response to this virus.

\section{Methods}

Animals. The animals used in this study were juvenile rhesus monkeys (Macaca mulatta). They were inoculated intravenously with simian immunodeficiency virus of macaques, strain 251 (hereafter referred to as SIV $_{\text {mac }}$ ) grown in Con A-activated human PBL. Blood samples and lymph node biopsies were obtained from the monkeys before and at various times after inoculation. Animals were maintained in accordance with the guidelines of the Committee on Animals for the Harvard Medical School and the Guide for the Care and Use of Laboratory Animals (DHHS Publication No. NIH 85-23, revised 1985).

Immunophenotypic analyses of peripheral blood and lymph node lymphocytes. PBL were prepared for one- or two-color immunophenotyping by flow cytometry using a whole blood lysis technique. For directly stained samples, $50 \mu \mathrm{l}$ of EDTA anticoagulated blood was diluted in $100 \mu \mathrm{l}$ of PBS/0.1\% BSA/0.02\% $\mathrm{NaN}_{3}$ with an appropriate amount of directly conjugated monoclonal antibody. Samples were incubated at room temperature for $60 \mathrm{~min}$, washed, and red blood cells lysed using a commercial lysing reagent (ImmunoLyse; Coulter Corp., Hialeah, FL). When cells were stained for leukocyte adhesion molecule-1 (LAM-1), an indirect technique was used where cells were first incubated with an anti-LAM-1 antibody in ascites form, washed, and then incubated with fluorescein-conjugated goat anti-mouse IgG $\left(\mathrm{F}(\mathrm{ab})_{2}\right.$ fragment [Jackson ImmunoResearch, Avondale, PA]). Cells were then washed twice with PBS supplemented with $100 \mu \mathrm{g} / \mathrm{ml}$ of irrelevant mouse IgG to block further binding of the goat antiserum and then stained with a second, phycoerythrin-conjugated monoclonal antibody. LN cells were prepared by gently teasing biopsy samples into a single cell suspension in HBSS supplemented with $2.5 \%$ FBS. $10^{6}$ lymph node cells were then stained with antibody as described above. All samples were fixed overnight in PBS with $1 \%$ formalin before routine analysis on an EPICS-C flow cytometer (Coulter Corp.).

Monoclonal antibodies used in these studies were human cell-specific reagents which were shown to react with conserved structures on cells of nonhuman primates. The antibodies used were: anti-CD4 (OKT4-FITC, OKT4-PE; Ortho Diagnostic Systems, Inc., Raritan, NJ); anti-CD8 (T8-FITC, T8-PE; Dako Corp., Carpinteria, CA); antiCD20 (B1-FITC), anti-CD25 (IL-2R1-FITC), anti-CD45RA (2H4RD1), anti-CD29 (4B4-RD1), anti-MHC Class II (I3-RD1) (all gener- 
ously supplied by Coulter Corp.). The anti-LAM-1 antibody (LAM110) was a gift of Dr. Thomas F. Tedder, Dana-Farber Cancer Institute, Boston, MA.

Cell cycle analyses. Quantitation of DNA in different subsets of lymph node cells was performed using a modification of previously described techniques $(4,5)$. Immunofluorescent labeling of cells with an anti-CD4,-CD8 or-CD20 fluorescein-conjugated antibody was first performed as described above. Cells were then fixed overnight at $4^{\circ} \mathrm{C}$ in PBS/0.5\% paraformaldehyde/0.05\% NP40, $\mathrm{pH}$ 7.4. Cellular RNA was digested by incubating fixed cells in $0.25 \mathrm{ml}$ PBS with $1 \mathrm{mg} / \mathrm{ml}$ RNAse (Ribonuclease A, Type I-A; Sigma Chemical Co., St. Louis, MO) for 45 min at $37^{\circ} \mathrm{C}$. Then, an equal volume of PBS with $1 \mathrm{mg} / \mathrm{ml}$ propidium iodide (Sigma Chemical Co.) was added and cells were incubated at room temperature at least $1 \mathrm{~h}$. Immediately before analysis, cells were washed once and resuspended in PBS.

Analysis was performed on an EPICS-C flow cytometer (Coulter Corp.) using $400 \mathrm{~mW}$ of $488 \mathrm{~nm}$ argon laser light. A gate was set on cells staining positively with fluorescein-conjugated cell surface markers using $90^{\circ}$ light scatter and log green fluorescence parameters. Cellular DNA was quantified in these gated cells by measuring red fluorescence $(>570 \mathrm{~nm}$ ). Doublet discrimination was performed by accepting only those events where peak and integrated red fluorescence signals were equal (6). The percentage of cells which had either $2 \mathrm{~N}$ quantity of DNA $\left(G_{0}, G_{1}\right.$ phases) or $>2 N$ quantity of DNA $\left(S, G_{2}, M\right.$ phases) were determined, and rates of proliferation in each subset were expressed as the percent of cells with $>2$ N DNA.

Histologic studies. Biopsies of $\mathrm{LN}$ were fixed in formalin, sectioned, and stained with hematoxylin and eosin. Histologic appearance was assessed by light microscopy.

Assays for SIV mac - specific cytotoxic activity. The ability of lymphocytes harvested from the peripheral blood or LN of SIV $_{\text {mac }}$-infected monkey to lyse autologous, $H$. papio-transformed B-lymphoblastoid target cells which expressed SIV $_{\text {mac }}$ gene products was assessed as previously described (7).

Estimates of effector cell frequencies in peripheral blood or lymph node lymphocytes were performed using a limiting dilution assay also previously described $(8,9)$.

\section{Results}

CD8+ cells are the predominant $T$ lymphocytes in rhesus monkey lymph nodes after $S I V_{\text {mac }}$ infection. The phenotypic and functional changes in lymphocytes in secondary lymphoid organs which occur in the first weeks after an AIDS virus infection remain poorly understood. To clarify these changes, we prospectively studied PBL and peripheral $\mathrm{LN}$ in a cohort of four rhesus monkeys inoculated with $\operatorname{SIV}_{\text {mac }}$. As illustrated in Fig. 1, within 3 wk of experimental infection with SIV $_{\text {mac }}$, monkeys showed a peripheral lymphopenia, due largely to a dramatic decrease in number of CD4+ cells. There was, however, no consistent change in the number of peripheral blood CD8 + cells. During this same period of time, all four monkeys developed mild but clinically evident enlargement of peripheral LN. As in the peripheral blood, a gradual but significant drop in the percentage of CD4+ cells was seen in LN. The percentage of LN B cells remained constant during the first 90 d after infection. Later, when the lymph nodes became markedly enlarged and histologic changes were evident, an increase in the absolute number of CD20+ lymphocytes (B cells) in peripheral blood and an increase in the percentage of $B$ cells in LN was documented.

Interestingly, a striking, early increase in the percentage of LN CD8+ lymphocytes was seen (Fig. 1). This appeared to reflect an absolute increase in CD8+ cells in LN. Despite a decrease in the percentage of CD4+ cells, the LN increased rather than decreased in size. Moreover, no reduction in the $T$ cell-rich paracortex was seen in these nodes. In fact, even after $100 \mathrm{~d}$ after SIV $_{\text {mac }}$ infection, at a time when B lymphocytes were increasing in number $\mathrm{LN}$, the fraction of $\mathrm{CD} 8+$ lymphocytes in the LN never decreased significantly. Therefore, the CD8 + lymphocyte remained the predominant $T$ cell in the lymph nodes of $\mathrm{SIV}_{\text {mac }}$-infected monkeys.

\section{PERIPHERAL BLOOD LYMPHOCYTES}
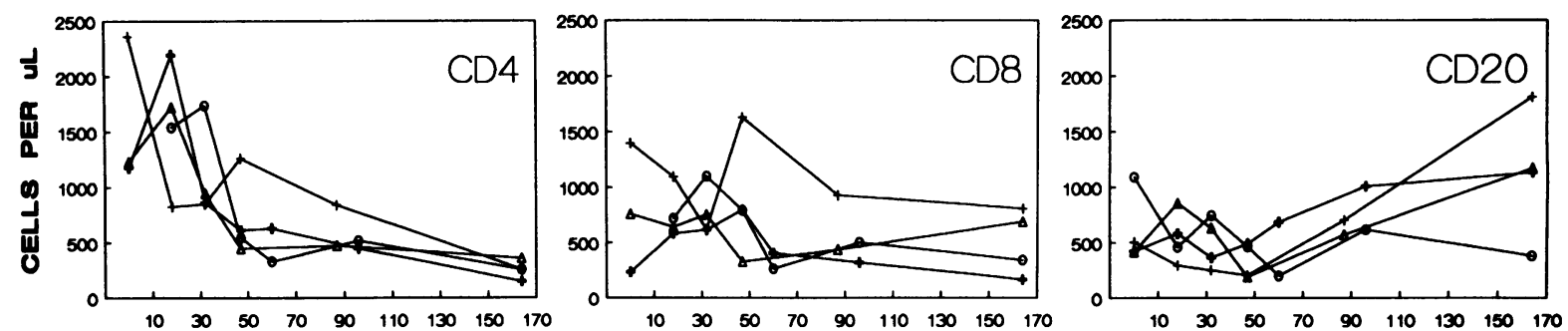

DAYS AFTER MFECTION

LYMPH NODE LYMPHOCYTES
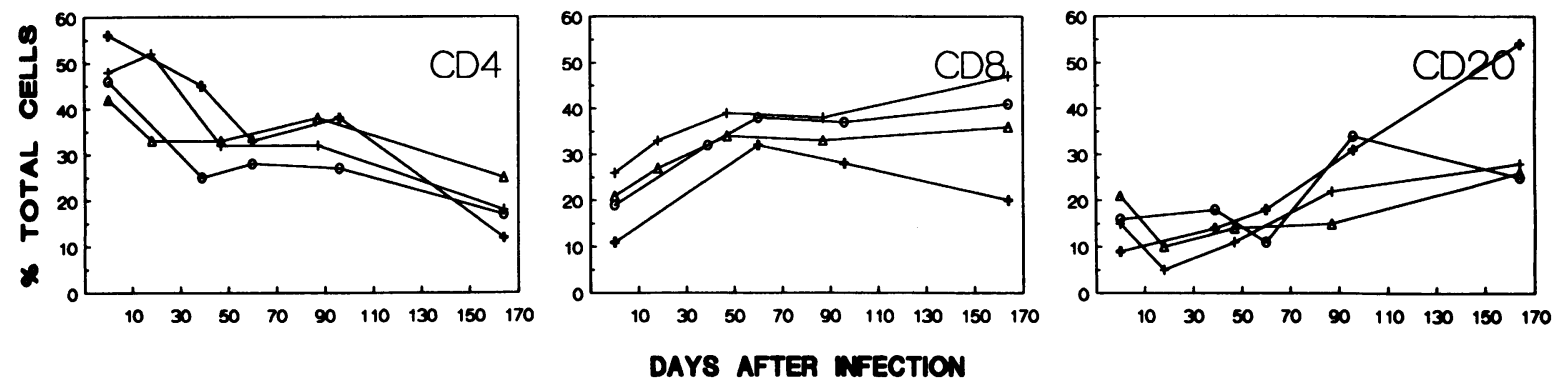

Figure 1. Change in phenotypic distribution of lymphocytes in peripheral blood and lymph nodes after infection with SIV $\mathrm{V}_{\text {mac }}$. Lymphocytes from peripheral blood or from lymph node biopsies were immunophenotyped by flow cytometric analysis. Each line represents data from one monkey. 
CD8+ lymph node $T$ cells have decreased expression of the "naive" lymphocyte marker CD45RA. As lymphocytes undergo a transition from "naive" to antigen-committed memory cells, the isoform of the CD45 molecule expressed on their surface changes from the RA to the RO form (10). To determine whether the expanded subset of CD8+ cells in lymph nodes of SIV $_{\mathrm{mac}}$-infected monkeys represented an expansion of committed memory cells responding to the SIV $_{\text {mac }}$ infection, expression of the CD45RA isoform was assessed. When CD8+ cells were examined by two-color flow cytometric analysis for the presence of CD45RA for $25 \mathrm{wk}$ after infection, we found a gradual but progressive decrease in its expression (Fig. 2). In fact, a similar decrease in CD45RA expression by CD4+ LN cells was also seen. The same trend was noted in CD4+ and CD8+ PBL, although results were less consistent between sampling time points and between animals. Available monoclonal antibodies which recognize the CD45RO isoform on human cells do not react with this molecular form of CD45 on rhesus monkey cells. Therefore, we were unable to assess monkey lymphocyte expression of the memory cell-associated isoform of CD45. We did, however, examine lymph node cells for expression of CD29, an integrin-family molecule expressed by PBL of healthy humans and nonhuman primates on CD45RO+ but not CD45RO- cells (11). We found relatively few CD29+ cells $(<20 \%)$ in lymph nodes of normal juvenile rhesus monkeys. Interestingly, this low percentage of CD29+ cells did not increase in PBL or LN CD8+ or CD4+ subsets after infection with SIV $_{\text {mac }}$ (data not shown).

$C D 8+T$ lymphocytes in lymph nodes of SIV $V_{\text {mac }}$-infected monkeys have increased expression of MHC class II and decreased expression of the leukocyte adhesion molecule LAM-1, but do not express CD25. In an attempt to define further this expanding CD8 + T lymphocyte subset, additional phenotypic studies were performed. The expression of the activation-associated cell surface molecule MHC class II by these CD8+ cells

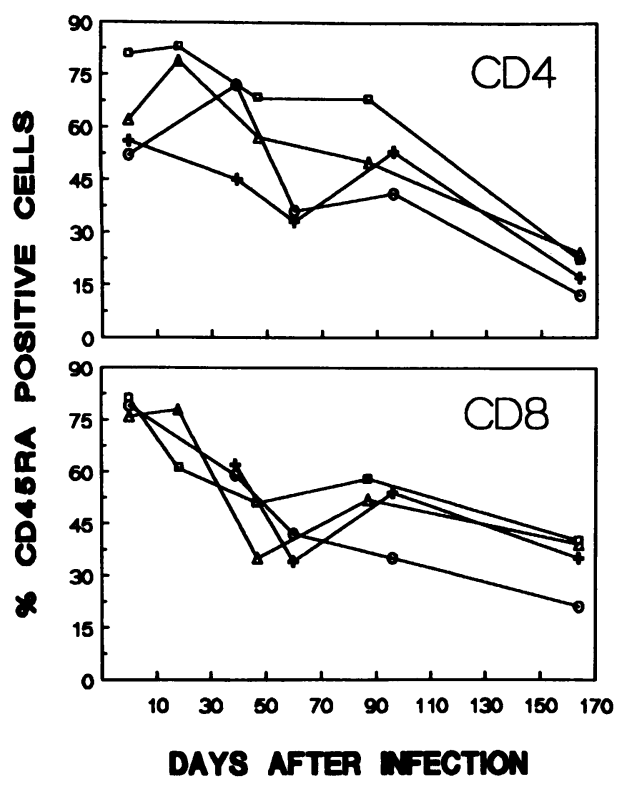

Figure 2. Expression of CD45RA decreases on CD4+ and CD8+ cells from lymph nodes after infection with SIV $_{\text {mac }}$. Lymphocytes from lymph node biopsies were analyzed by two-color flow cytometry. Each line represents data from one monkey.

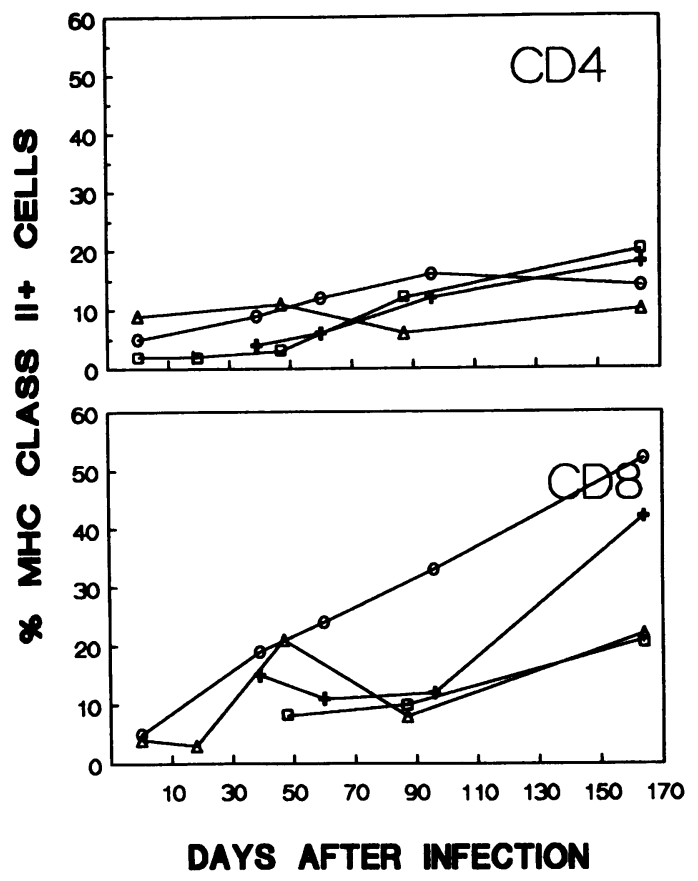

Figure 3. Expression of MHC class II increases on CD8+ cells but not on CD4+ cells after infection with SIV $_{\operatorname{mac}}$. Lymphocytes from lymph node biopsies were analyzed by two-color flow cytometry. Each line represents data from one monkey.

was assessed. As shown in Fig. 3, MHC class II expression by $\mathrm{CD} 8+$ cells in $\mathrm{LN}$ rose significantly after infection. In two monkeys $>30 \%$ of CD8 + cells expressed MHC class II. An increase in MHC class II was not observed in CD4+ lymph node cells.

At approximately the same time that MHC class II expression was noted on LN CD8+ cells, MHC class II expression also increased on PBL (Table I). However, unlike LN where MHC class II expression increased predominantly on CD8+ cells, in PBL both CD4+ and CD8+ cells expressed MHC class II.

The observation of increased MHC class II expression on CD8+ lymphocytes suggested that these cells might be activated. We, therefore, examined lymph node cells for other activation-associated changes. LAM-1, a member of the recently described selectin family of leukocyte adhesion/homing molecules, is rapidly modulated from the cell surface of lymphocytes during in vitro activation $(12,13)$. As shown in Fig. 4, the

Table I. MHC Class II+ Cells in Peripheral Blood

\begin{tabular}{ccc}
\hline $\begin{array}{c}\text { Days after } \\
\text { infection }\end{array}$ & \multicolumn{2}{c}{ Mean MHC-II+ cells per $\mu \mathbf{1}^{*}$} \\
\cline { 2 - 3 } $18-39$ & $70 \pm 30$ & CD8 subset \\
$47-60$ & $40 \pm 20$ & $50 \pm 30$ \\
82 & $490 \pm 220$ & $40 \pm 10$ \\
$88-93$ & $320 \pm 150$ & $290 \pm 190$ \\
165 & $150 \pm 80$ & $190 \pm 120$ \\
& & $200 \pm 70$ \\
\hline
\end{tabular}

* Mean $\pm \mathrm{SD}, n=4$. 
majority of CD4+ and CD8+ lymphocytes in the $\mathrm{LN}$ of normal monkeys are strongly reactive with an anti-LAM-1 antibody. However, in the $\mathrm{LN}$ of four of five $\mathrm{SIV}_{\text {max }}$-infected rhesus monkeys, there was a dramatic decrease in LAM-1 expression by CD8+ lymphocytes with little or no change in the LAM-1 expressed on CD4+ cells. These observations further support the notion that CD8+ lymphocytes are an activated subset of lymphocytes in SIV $_{\operatorname{mac}}$ infection.

Surprisingly, the expression of the IL-2 receptor (CD25) remained low on the CD8+ (Fig. 5) as well as CD4+ lymphocytes (data not shown).

$C D 8+T$ lymphocytes are nonreplicating in the lymph nodes of $S I V_{\text {mac }}$-infected rhesus monkeys. Thus, CD8+ lymphocytes expressing activation-associated molecules appear in LN in increased number after SIV $_{\operatorname{mac}}$ infection. This could represent clonal expansion of CD8 + cells within LN or recruitment of cells from other locations. To clarify this issue, we assessed the relative rate of proliferation of the lymphocyte subpopulations within the LN. We utilized a multiparameter flow cytometric technique that allowed simultaneous analysis of immunophenotype and quantitation of cellular DNA. Using this approach, proliferating cells in different phases of the cell cycle could be identified in specific cell subpopulations by propodium iodide fluorescence (Fig. 6). By quantitating DNA and measuring the percentage of cells in the $S, G_{2}$, or $M$ phase of the cell cycle, we were able to estimate their relative proliferation kinetics. The rates of proliferation are low ( $<4 \%$ cycling cells) in $T$ and B cells in normal rhesus monkey lymph nodes (data not shown) and in monkey lymph node cells assessed immediately after SIV $_{\text {mac }}$ infection. As shown in Fig. 7, there was no increase in the rate of proliferation in the CD8+ subset of lymphocytes through day 164 after SIV $_{\text {mac }}$ infection. Only when follicular hyperplasia became evident histologically, was there a measurable increase in the rate of proliferation of $B$ cells in the $\mathrm{LN}^{\mathrm{N}} \mathrm{SIV}_{\text {mac }}$ infected monkeys. Therefore, CD8+ lymphocytes, while increased in number, do not represent a rapidly proliferating subset of cells in $\mathrm{LN}$ after SIV $_{\text {mac }}$ infection.

T lymphocyte population changes preceded any changes evident in the histologic appearance of lymph nodes. The histologic appearance of the LN was determined by light microscopic examination of hematoxylin-eosin stained sections. LN biopsies were obtained before inoculation and approximately $20,50,90$, and $160 \mathrm{~d}$ after infection with SIV $_{\text {mac }}$. Although a shift in cell phenotype from predominantly $\mathrm{CD} 4+$ to $\mathrm{CD} 8+$, as

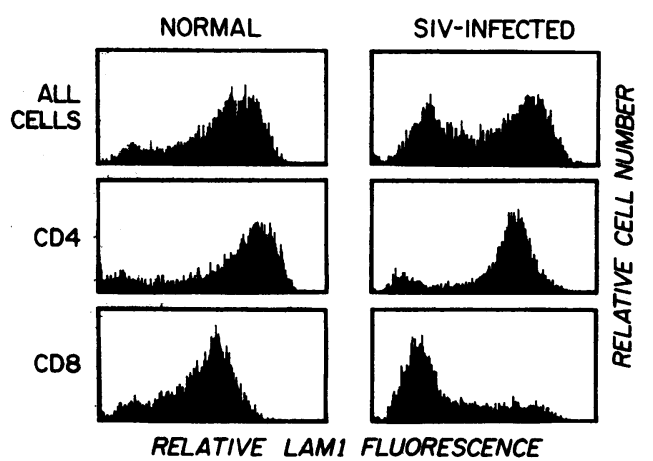

Figure 4. Expression of LAM-1 is decreased on CD8+, but not CD4+ LN cells after infection SIV $_{\text {mac }}$. Lymph node cells were obtained from a normal monkey and from a monkey $\sim 300 \mathrm{~d}$ after infection with SIV $_{\text {mac }}$.
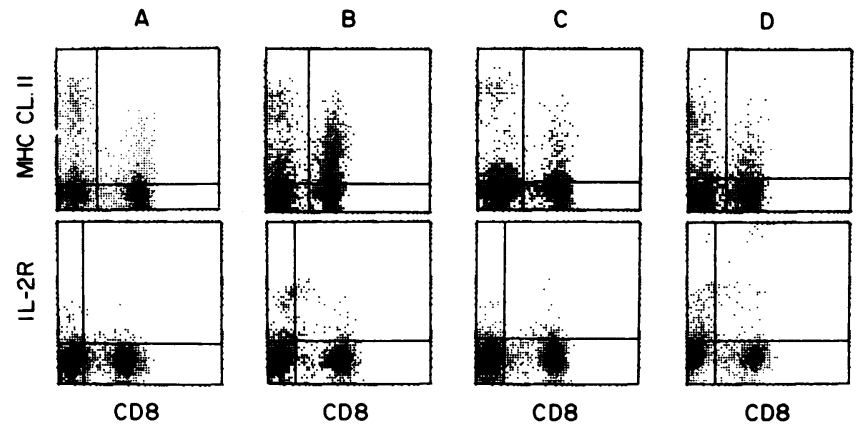

Figure 5. MHC class II is expressed, but IL-2R is absent on CD8+ cells. Lymphocytes from lymph node biopsies of four monkeys $(A-D)$ taken 80-100 d after infection with SIV $_{\operatorname{mac}}$ were immunophenotyped by a two-color technique. Axes represent relative fluorescence for the indicated antigen.

determined by flow cytometric analysis, began as early as $20 \mathrm{~d}$ postinfection (Fig. 1), the histologic appearance of the $\mathrm{LN}$ remained normal until day 87 in two monkeys and day 96 in two others. Fig. 8 illustrates the changes in the morphology of LN from one rhesus monkey after experimental infection with $\mathrm{SIV}_{\text {mac }}$. At 16 and $47 \mathrm{~d}$ after inoculation, the LN were morphologically the same as the preinoculation $L N$. There were a few primary follicles and an occasional small secondary follicle at the periphery of the nodes and the paracortex was normal. LN changes consistent with lymphadenopathy, as previously described in SIV $_{\text {mac }}$-inoculated macaques (14) were seen at day 87. At that time, the $\mathrm{LN}$ from this monkey had numerous hyperplastic secondary follicles with large irregularly shaped germinal centers both at the periphery and deep in the node. The germinal centers were active, having a large number of mitoses and tingible body macrophages, and the mantle zones were small. The paracortical T-cell regions were much smaller than previously seen. This alteration in architecture was also seen in the biopsy sample at $164 \mathrm{~d}$ after inoculation. Thus, dramatic changes in the LN T-cells occurred even before histologically detected abnormalities were evident.

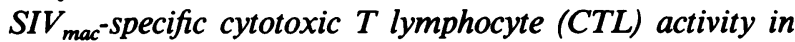
$L N$ lymphocytes and $P B L$. We wished to determine if the large increase in activated CD8+ cells in $\mathrm{LN}$ was due to an increase

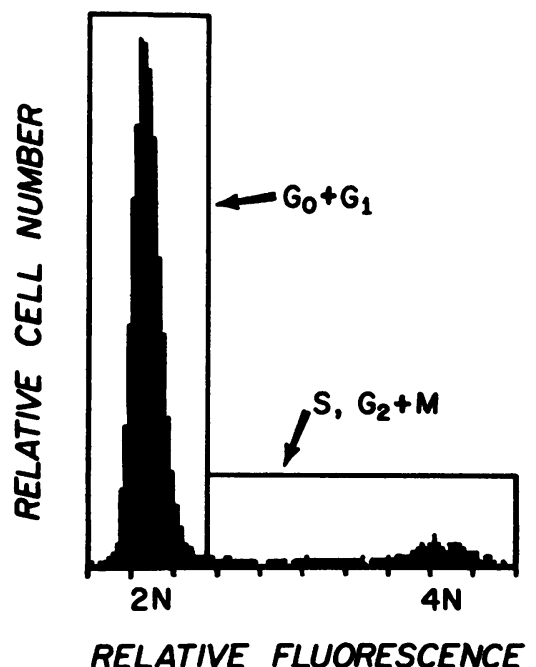

Figure 6. Fluorescence histogram of lymphocytes stained with propidium iodide. Based on quantitation of DNA by this method, relative distribution of cells in each phase of the cell cycle was estimated. 


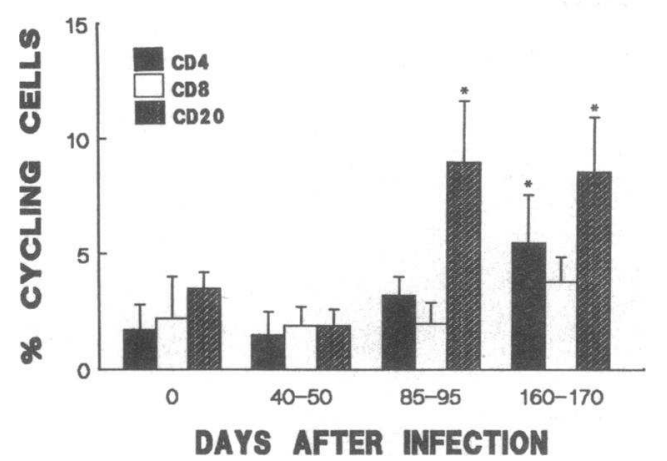

Figure 7. Percentage of lymph node cells in CD4, CD8, or CD20 subset which are cycling $\left(S, G_{2},+M\right.$ phases). Samples obtained at the indicated times after infection with SIV $_{\text {mac }}$ were simultaneously immunophenotyped and stained with propidium iodide. *Significant differences from day $0(P<0.05)$.

in virus-specific CTL. We, therefore, performed assays to quantitate SIV $_{\text {mac }}$-gag-specific CTL lysis in PBL and LN cells. As shown in Fig. 9, significant SIV $_{\text {mac }}$-gag-specific lysis was mediated by the cells of four of eight monkeys tested. In all animals, good correlation existed between CTL activity measurable in peripheral blood and that measurable in LN. However, when we compared the CTL activity with the percentage of CD8+ cells expressing MHC class II, no correlation existed (Fig. 9). Therefore, the CD8 + cell population appearing in $\mathrm{LN}$ after SIV $_{\text {mac }}$ infection did not appear to be a simple expansion of virus-specific CTL.

We further investigated the SIV $_{\text {mac }}$-specific CTL activity directed toward other virus proteins, and using a limiting dilution assay, were able to estimate effector cell frequencies in PBL and LN. As shown in Table II, both the CTL specificity and effector cell frequency estimates were similar in lymphocytes from the peripheral blood and LN. However, the frequency of cells with SIV $_{\text {mac }}$-specific cytolytic activity was only $\sim$ 1-10 CTL per $10^{6}$ lymphocytes. This effector cell frequency is similar to that measured in PBL from HIV-infected humans (15). Therefore, because the number of activated CD8+ cells in $\mathrm{LN}$ is orders of magnitude larger than the estimated frequency of CTL, it seems unlikely that virus-specific CTL constitute a significant proportion of the newly expanded CD8+, MHC class II+ LN T cell subset.

\section{Discussion}

The experimental infection of rhesus monkeys with SIV $_{\text {mac }}$ provides a model for the study of early pathogenic events in AIDS which cannot be easily examined in HIV-infected humans. The studies reported here show that early after SIV $_{\text {mac }}$ infection in rhesus monkeys, a shift occurs from CD4+ to CD8+ lymphocyte predominance. An increase in CD8+ cells was evident in LN, but not in the peripheral blood. Despite this shift from CD4+ to CD8+ predominance, the LN had a normal histologic appearance. In fact, these $T$ lymphocyte changes preceded B cell hyperplasia by 5-7 wk. By virtue of their increase in number and expression of activation antigens, these CD8+ lymphocytes are likely to be important in the immunopathogenesis of AIDS.

Lymphocytes from the peripheral blood are used clinically to estimate total body lymphocyte number and function in
AIDS and in other illnesses. However, the blood compartment contains only $2 \%$ of the body's total lymphocytes. In many clinical conditions severe disturbances within the secondary lymphoid organs are either modestly reflected or not reflected at all in the peripheral blood hemogram (1). We, therefore, were interested in comparing the changes in phenotypic distribution of blood lymphocytes with lymphocytes in secondary lymphoid organs after SIV $_{\text {mac }}$ infection. In a cohort of monkeys, the PBL did reflect the early decrease in CD4+ lymphocytes and the late increase in CD20+ lymphocytes seen in LN. However, the increase in CD8+ cells which occurred in LN

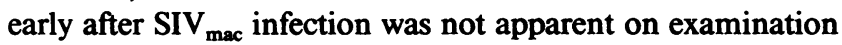
of blood lymphocytes. Similarly, the preferential expression of MHC class II on CD8+ cells in LN was not mirrored in the blood; in PBL both CD4+ and CD8+ cells became MHC class II positive. These findings underscore the problem of using lymphocytes from blood to estimate the phenotypic distribution of total body lymphocytes. However, CTL activity observed in LN always paralleled closely that seen in peripheral blood, suggesting that CTL activity in PBL is reflective of this activity in other compartments as well.

A large proportion of the LN CD8+ cells were activated because they expressed MHC class II but not LAM-1. CD25, however, was not expressed by these CD8+ LN cells. A similar pattern of activation antigen expression has been seen in CD8+ PBL of humans later in the course of infection with HIV (1619). The present study, therefore, indicates that such changes in the activation state of CD8+ cells occurs throughout the body. These activated CD8+ lymphocytes, thus, represent a subset of considerable size. While increased in number, these CD8+ cells do not appear to be undergoing rapid proliferation within the LN. This observation is consistent with studies in HIV-infected humans which showed that CD8+, MHC class II+ PBL failed to proliferate in vitro and had decreased clonogenic potential (16). The function that these cells may play, either in delaying or promoting disease progression, remains uncertain.

The CD8+ lymphocyte plays a central role in containing viral infections. Not surprisingly, CD8 + lymphocytes have been identified in HIV - and SIV-infected individuals which are capable of suppressing virus replication or lysing specifically virus-infected cells in vitro (20-23). In the PBL of HIV-infected humans, this virus-specific CTL activity resides in the CD8+, MHC class II+ subset (24). Likewise, the infiltrating lymphocytes in HIV-related alveolitis are CD8 + and have both effector $T$ cell phenotype and function $(22,23)$. We, therefore, wondered whether these activated CD8+ lymphocytes from the LN might represent significant expansion of a similar virusspecific CTL subset capable of controlling SIV $_{\text {mac }}$ spread in monkeys. However, no correlation was seen between the number of CD8+, MHC class II+ lymphocytes, and virus-specific CTL activity. In fact, the lymphocytes from some monkeys with a large MHC class II+, CD8+ subset lacked measurable SIV $_{\text {mac }}$-specific CTL activity. Furthermore, in monkeys with measurable CTL activity, the calculated env-, gag-, and polspecific CTL effector cell frequencies in $\mathrm{LN}$ were extremely small when compared to the total number of activated CD8+ cells in these tissues. Therefore, neither functional nor statistical data support the notion that these CD8 + cells are virus-specific CTL.

The significance of the shift of CD8+ lymphocytes from CD45RA + to CD45RA - remains unclear. In both the mouse 

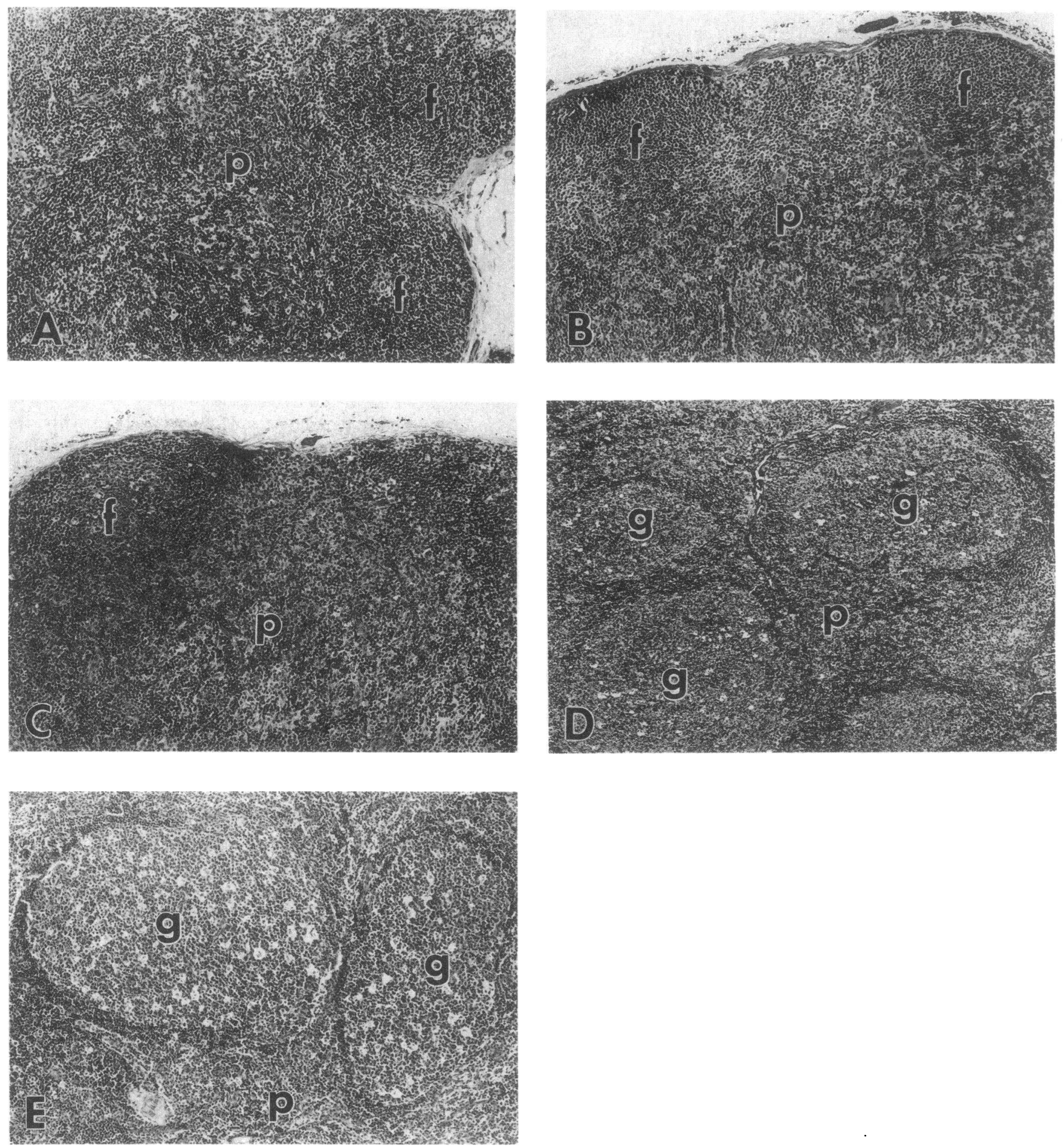

Figure 8. Morphologic changes in lymph nodes from one rhesus monkey before and at interals after inoculation with SIV mac . The preinoculation biopsy $(A)$ is similar to those at $16(B)$ and $47(C)$ days after inoculation. There are small follicles (f) and a normal parracortex (p). Hyperplastic follicles with large germinal center $(\mathrm{g})$ were seen at $87(D)$ and $164(E)$ d postinoculation. Hematoxylin-eosin, $A-C, E \times 82.5 ; D \times 62.5$.

and in man, the lymphocytes responsible for this MHC class I-restricted lysis have a memory cell phenotype $(25,26)$. One would expect, therefore, AIDS virus-specific CTL to be CD45RA-. Yet while CD8+ cells became increasingly CD45 RA-, no increase in virus-specific lysis was observed. Further characterization of the memory status of these cells was not possible because reagents which recognize the CD45RO iso- form are not available in monkeys. However, no increased staining for CD29 (an antigen present on the population reciprocal of CD45RA+) of CD8+ cells was noted after infection. Thus, these CD45RA-CD8+ cells may represent either normal antigen-activated memory cells or cells in an abnormal maturational stage induced in response to infection with SIV $_{\text {mac }}$. 


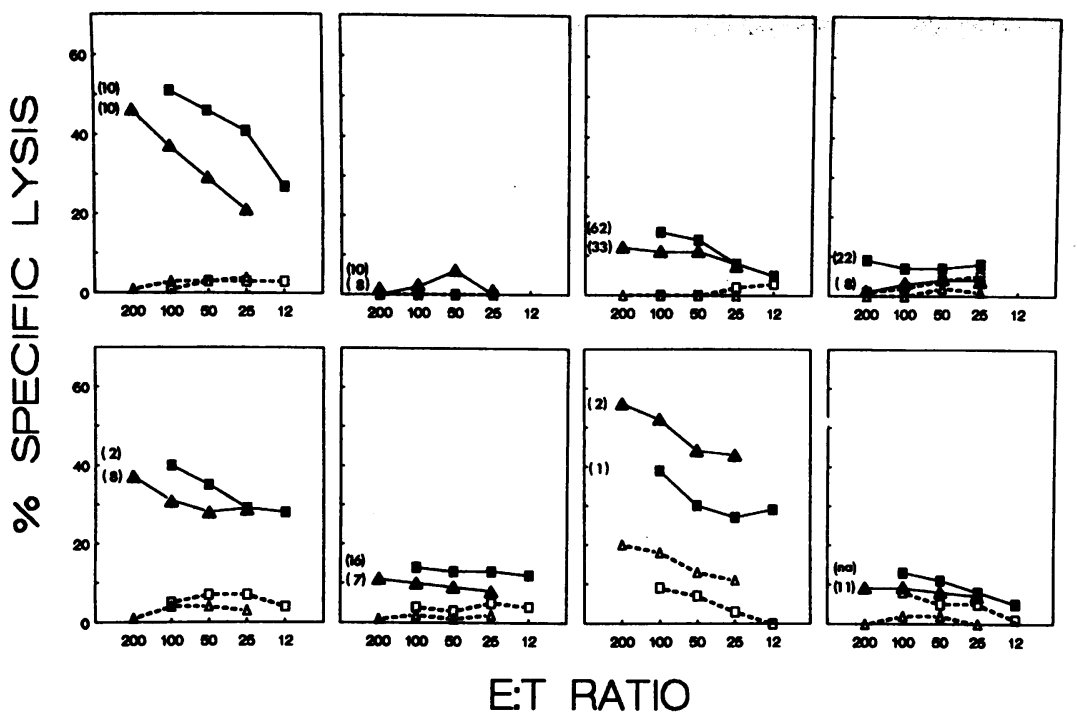

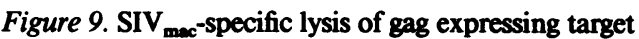
cells by PBL ( $(\Delta)$ or lymph node lymphocytes ( $)$ from eight infected monkeys as described in Methods. Solid lines represent lysis of SIV $_{\max }$ gag-expressing autologous target cells at different effector to target (E:T) ratios. (Dashed lines) Lysis of control targets expressing an irrelevant gene product. Numbers in parentheses indicate percentage of effector CD8 + cells which expressed MHC class II in each monkey.
Whereas the expansion of this $\mathrm{CD} 8+, \mathrm{MHC}$ class II+ subset failed to correlate with SIV $_{\text {mac }}$-specific cytotoxicity, it does not mean that the virus-specific effector cells are not within this subset. In fact, SIV $_{\text {mac }}$-specific CTL activity in infected monkeys probably resides in this phenotypic subset just as in HIVinfected humans. These findings did, however, force us to consider that some of the cells being expanded in the subset might be serving a regulatory rather that an effector function. This hypothesis is consistent with studies performed on HIV-infected humans whose LN have been shown to contain increased "suppressor" CD8 + lymphocytes with no increase in "cytotoxic" CD8+ cells (27). In fact, activated CD8+ lymphocytes arise in a variety of virus infections. CD8+ lymphocytes from the lungs of late-stage HIV-infected humans can suppress HIV-specific CTL activity (28). Infection in man with herpes viruses such as Epstein-Barr virus and cytomegalovirus can also result in a CD8+ lymphocytosis (29-31). The CD8+ cells which arise after these infections have the ability to suppress profoundly various immunologic functions (30). Thus, the pathogenesis of AIDS virus infections may result, in part, from events mediated by this expanded subset of activated CD8+ lymphocytes.

Table II. Estimated CTL Frequency (per $10^{6}$ Lymphocytes)

\begin{tabular}{cccccccc}
\hline & \multicolumn{3}{c}{ Peripheral blood } & & \multicolumn{3}{c}{ Lymph node } \\
\cline { 2 - 3 } \cline { 6 - 7 } ID & env & gag & pol & & env & gag & pol \\
\hline 163 & $1.0-3.0$ & $0.3-0.9$ & $<0.3$ & & $0.3-0.9$ & $<0.3$ & $<0.3$ \\
165 & $2.3-7.6$ & $<0.3$ & $<0.3$ & $0.2-12.6$ & $<0.3$ & $<0.3$ \\
174 & $5.7-8.8$ & $0.0-3.3$ & $0.1-1.0$ & & $1.1-4.1$ & $1.1-4.1$ & $<0.3$ \\
246 & $<0.3$ & $<0.3$ & $<0.3$ & & $1.0-5.0$ & $<0.3$ & $<0.3$
\end{tabular}

A limiting dilution assay (9) was used to estimate CTL frequency. Effector cells were either fresh PBL or fresh LN lymphocytes obtained from biopsies. Target cells were autologous, $H$. papio-transformed B lymphoblastoid cells which were infected with a recombinant vaccinia virus expressing SIV $_{\text {mac }}$-env, -gag or -pol gene products. Data are expressed as CTL $/ 10^{6}$ lymphocytes ( $95 \%$ confidence limit).

\section{Acknowledgments}

The authors would like to thank Dr. Thomas F. Tedder for supplying the anti-LAM-1 monoclonal antibody, and Shelley Kotlikoff for help in preparation of this manuscript.

This work was supported in part by a Public Health Service Special Emphasis Career Award in Laboratory Animal Science RR00055 and by Public Health Service grants RR00168, AI20729, CA50139, and CA34979.

\section{References}

1. Westermann, J., and R. Pabst. 1990. Lymphocyte subsets in the blood: a diagnostic window on the lymphoid system? Immunol. Today. 11:406-410.

2. Daniel, M. D., N. L. Letvin, N. W. King, M. Kannagi, P. K. Sehgal, R. D. Hunt, P. J. Kanki, M. Essex, and R. C. Desrosiers. 1985. Isolation of a T cell tropic HTLV-III-like retrovirus from macaques. Science (Wash. DC). 228:12011204.

3. Letvin, N. L., M. D. Daniel, P. K. Sehgal, R. C. Desrosiers, R. D. Hunt, L. M. Waldron, J. J. Mackey, D. K. Schmidt, L. V. Chalifoux, and N. W. King. 1985. Induction of an AIDS-like disease in macaques monkeys with $T$ cell tropic retrovirus STLV-III. Science (Wash. DC). 230:71-73.

4. Gray, J. W., and P. Coffino. 1979. Cell cycle analysis by flow cytometry. Methods Enzymol. 58:233-248.

5. Frankfurt, O. S. 1980. Flow cytometric analysis of double-stranded RNA content distributions. J. Histochem. Cytochem. 28:663-669.

6. Sharpless, T., F. Traganos, Z. Darzynkiewicz, and M. R. Melamed. 1975. Flow cytofluorimetry: discrimination between single cells and cell aggregates by direct size measurements. Acta Cytologica. 19:577-581.

7. Miller, M. D., C. I. Lord, V. Stallard, G. P. Mazzara, and N. L. Letvin. 1990. Gag-specific cytotoxic T lymphocytes in rhesus monkeys infected with the simian immunodeficiency virus of macaques. J. Immunol. 144:122-128.

8. Lindahl, K. F., and D. B. Wilson. 1977. Histocompatibility antigen-activated cytotoxic T lymphocytes. II. Estimates of the frequency and specificity of precursors. J. Exp. Med. 145:508-522.

9. Yamamoto, H., M. D. Miller, D. I. Watkins, G. B. Snyder, N. E. Chase, G. P. Mazarra, L. Gritz, D. Panicali, and N. L. Letvin. 1990. Two distinct lymphocyte populations mediate simian immunodeficiency virus envelope-specific target cell lysis. J. Immunol. 145:3740-3746.

10. Sanders, M. E., M. W. Makgoba, and S. Shaw. 1988. Human naive and memory $T$ cells: reinterpretation of helper-inducer and suppressor-inducer subsets. Immunol. Today. 9:195-199.

11. Morimoto, C., N. L. Letvin, A. W. Boyd, M. Hagan, H. M. Brown, M. M. Kornacki, and S. F. Schlossman. 1985. The isolation and characterization of the human helper inducer T cell subset. J. Immunol. 134:3762-3769.

12. Tedder, T. F., A. C. Penta, H. B. Levine, and A. S. Freedman. 1990. Expression of the human leukocyte adhesion molecule, LAM1. Identity with the TQ1 and Leu-8 differentiation antigens. J. Immunol. 144:532-540.

13. Spertini, O., G. S. Kansas, K. A. Reimann, G. R. Mackay, and T. F. Tedder. 1991. Function and evolutionary conservation of distinct epitopes on the leukocyte adhesion molecule-1 (TQ-1, Leu-8) that regulates leukocyte migration. J. Immunol. 147:942-949. 
14. Chalifoux, L. V., D. J. Ringler, N. W. King, P. K. Sehgal, R. C. Desrosiers, M. D. Daniel, and N. L. Letvin. 1987. Lymphadenopathy in macaques experimentally infected with the simian immunodeficiency virus (SIV). Am. J. Pathol. 128:104-110.

15. Hoffenbach, A., P. Langlade-Demoyen, G. Dadaglio, E. Vilmer, F. Michel, C. Mayaud, B. Autran, and F. Plata. 1989. Unusually high frequencies of HIV-specific cytotoxic T lymphocytes in humans. J. Immunol. 142:452-462.

16. Pantaleo, G., S. Koenig, M. Baseler, H. C. Lane, and A. S. Fauci. 1990. Defective clonogenic potential of CD8 $+\mathrm{T}$ lymphocytes in patients with AIDS Expansion in vivo of a nonclonogenic $\mathrm{CD} 3+\mathrm{CD} 8+\mathrm{DR}+\mathrm{CD} 25-\mathrm{T}$ cell population. J. Immunol. 144:1696-1704.

17. Zeigler-Heitbrock, H. W. L., D. Stachel, T. Schlunk, L. Gurtler, W. Schramm, M. Froschl, S. R. Bogner and G. Riethmuller. 1988. Class II (DR) antigen expression on CD8+ lymphocyte subsets in acquired immunodeficiency syndrome (AIDS). J. Clin. Immunol. 8:473-478.

18. Giorgi, J. V., and R. Detels. 1989. T cell subset alterations in HIV-infected homosexual men: NIAID multicenter AIDS cohort study. Clin. Immunol. Immunopathol. 52:10-18.

19. Nicholson, J. K. A., J. S. McDougal, T. J. Spira, G. D. Cross, B. M. Jones, and E. L. Reinherz. 1984. Immunoregulatory subsets of the $T$ helper and $T$ suppressor cell populations in homosexual men with chronic unexplained lymphadenopathy. J. Clin. Invest. 73:191-201.

20. Tsubota, H., C. I. Lord, D. I. Watkins, C. Morimoto, and N. L. Letvin. 1989. A cytotoxic T lymphocyte inhibits acquired immunodeficiency virus replication in peripheral blood lymphocytes. J. Exp. Med. 169:1421-1434.

21. Walker, B. D., D. J. Moody, D. P. Stites, and J. A. Levy. 1986. CD8+ lymphocytes can control HIV infection in vitro by suppressing virus replication. Science (Wash. DC). 234:1563-1566.

22. Plata, F., B. Autran, L. P. Martins, S. Wain-Hobson, M. Raphael, C. Mayaud, M. Denis, J. M. Guillon, and P. Debre. 1987. AIDS virus-specific cytotoxic T lymphocytes in lung disorders. Nature (Lond.) 328:348-351.
23. Autran, B., C. M. Mayaud, M. Raphael, F. Plata, M. Denis, A. Bourguin, J. M. Guillon, P. Debre, and G. Akoun. 1988. Evidence for a cytotoxic T-lymphocyte alveolitis in human immunodeficiency virus-infected patients. AIDS. 2:179-183.

24. Panteleo, G., A. DeMaria, S. Koenig, L. Butini, B. Moss, M. Baseler, H. C. Lane, and A. S. Fauci. 1990. CD8+ T lymphocytes of patients with AIDS maintain normal broad cytolytic function despite the loss of human immunodefciency virus-specific cytotoxicity. Proc. Natl. Acad. Sci. USA. 87:4818-4822.

25. Tabi, Z., F. Lynch, R. Ceredig, J. E. Allen, and P. C. Doherty. 1988. Virus-specific memory $T$ cells are Pgp-1+ and can be selectively activated with phorbol ester and calcium ionophore. Cell. Immunol. 113:268-277.

26. Sohen, S., D. M. Rothstein, T. Tallman, D. Gaudette, S. F. Schlossman, and C. Morimoto. 1990. The functional heterogeneity of CD8 + cells defined by anti-CD45RA (2H4) and anti-CD29 (4B4) antibodies. Cell. Immunol. 128:314328.

27. Wood, G. S., B. F. Burns, R. F. Dorfman, and R. A. Warnke. 1986. In situ quantitation of lymph node helper, suppressor, and cytotoxic $T$ cell subsets in AIDS. Blood. 67:596-603.

28. Joly, P., J.-M. Guillon, C. Mayaud, F. Plata, I. Theodorou, M. Denis, P. Debre, and B. Autran. 1989. Cell-mediated suppression of HIV-specific cytotoxic T lymphocytes. J. Immunol. 143:2193-2201.

29. Carney, W. P., R. H. Rubin, R. A. Hoffman, W. P. Hansen, K. Healey, and M. S. Hirsch. 1981. Analysis of T lymphocyte subsets in cytomegalovirus mononucleosis. J. Immunol. 126:2114-2116.

30. Reinherz, E. L., C. O'Brien, P. Rosenthal, and S. F. Schlossman. 1980. The cellular basis for viral-induced immunodeficiency: analysis by monoclonal antibodies. J. Immunol. 126:1269-1274.

31. Tomkinson, B. E., D. K. Wagner, D. L. Nelson, and J. L. Sullivan. 1987. Activated lymphocytes during acute Epstein-Barr virus infection. J. Immunol. 139:3802-3807. 